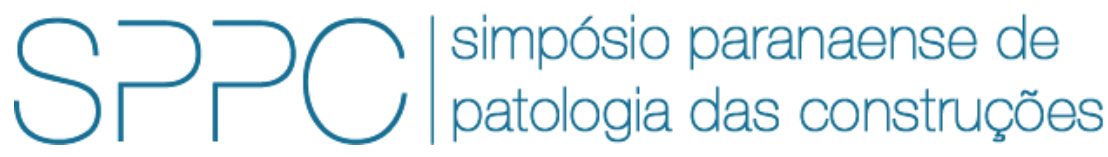

ISSN 2526-7248 artigo n. 2SPPC1013, pp. 144-158, 2017

\title{
Falha de concretagem de pilares e suas consequências na estrutura da edificação
}

\author{
Raquel Munaro e Edna Possan² \\ 1 Arquiteta e Urbanista, Universidade de Caxias do Sul/ UCS, raquel.munaro@gmail.com \\ 2 Prof. Dra, Universidade Federal da Integração Latino Americana, epossan@gmail.com
}

\begin{abstract}
RESUMO: Este estudo busca verificar os dados de concretagem de pilares do terceiro subsolo, de uma edificação multifamilar na cidade de Caxias do Sul, RS, tendo em vista diagnosticar o motivo da falha encontrada na junta de concretagem dos pilares e se houve consequências à estrutura, uma vez que esse problema gerou a exposição das armaduras na cabeça de alguns pilares. A metodologia utilizada é a investigação de caráter qualitativo, por meio da pesquisa explicativa e estudo de caso. Contempla a análise do fenômeno observado, com coleta de dados das condições da concretagem, verificando a resistência à compressão do concreto com amostragem de cada caminhão utilizado nos pilares afetados, através de ensaio em corpos de prova e testemunhos extraídos in loco, ensaio de esclerometria em pilares do pavimento superior, identificação da dosagem do concreto, bem como a caracterização climática no lançamento do concreto, a fim de identificar a origem do problema. Após a análise dos dados foi possível evidenciar a falha na dosagem e concretagem assim como propor alternativa para executar a correção mais adequada da manifestação patológica apresentada.
\end{abstract}

Palavras-chave: Falha de concretagem. Concreto armado. Junta de concretagem.

ABSTRACT: This study aims to verify the concreting columns data from the third underground floor, in a multi-family building, in Caxias do Sul, Rio Grande do Sul, bearing in mind diagnosing the failure reason, found at the columns concreting joint and if it was any structural damage, once this problem caused the rebar exposure on top plate of some pillars. The methodology used is quality investigation, through an explanatory research along with the study and identification of the event that caused the imperfection on the pillars. This only case study includes an analysis of the observed problem; data collection of the concreting conditions, in order to verify the concrete compression resistance with a sample from every kind of concrete used on the affected pillars, through previous tests on testing pillars and the family testimony collected in loco; sclerometry tests on the upper floor pillars; concreting dosage identification, as well as the climatic characterization when the concrete was used, in order to identify the problem origin. After a data analysis, it was possible to verify the failure in the concrete dosage and in the concreting process steps. It was also possible to propose a solution to execute the most accurate correction for this specific building pathology.

Keywords: Concreting failure. Reinforced concrete. Concreting joint. Pathological manifestation. 


\section{Introdução}

Sabe-se que concreto é o segundo material mais utilizado no mundo perdendo apenas para a água [8]. Ele é um aglomerado constituído de agregados (areia e brita), cimento como aglutinante e água. Pode ainda agregar a sua composição aditivos dos mais variados, para cura rápida ou mais demorada, para maior plasticidade, dentre outros. O concreto armado, que é a massa de concreto associada com barras de aço, possui resistência aos esforços de tração e flexão, já o concreto 'puro' possui alta resistência à compressão [7]. A NBR 6118:2014, [3], define como concreto armado o elemento estrutural cujo comportamento depende da aderência entre concreto e armadura, e os quais não se aplicam alongamento iniciais da armadura antes da materialização dessa aderência'. Por essas características e também por sua plasticidade que permitem as dimensões e formas mais variadas, com alto grau de resistência, quando dimensionado e especificado de acordo com a solicitação exigida pela estrutura proposta, o concreto armado é amplamente utilizado na construção civil.

A gama de variações de concretos é extensa, cada denominação faz referência à suas características mais pronunciadas, cita-se como exemplos o concreto bombeável, cuja qualidade é sua fluidez para possibilitar seu lançamento a grandes distâncias, horizontal e vertical; o microconcreto ou grout, com agregados de pequeno diâmetro e aditivos especiais para garantir fluidez. [9] e o concreto auto adensável com grande resistência a segregação, coesão e características fluídica, facilitando o lançamento do concreto por sua trabalhabilidade e estabilidade, fazendo-o atingir a totalidade da forma pilar, percorrendo grandes distâncias, mesmo com obstáculos no caminho [12], envolvendo a armadura com maior facilidade. Existem outros tipos, de concretos (leve, de alta resistência, rolado, projetados, celular, colorido dentre outros), porém os exemplos citados e caracterizados foram escolhidos por terem sido os utilizados no estudo de caso apresentado a seguir.

Ainda é importante comentar sobre a dosagem, chamada de traço, desse material e seu correto proporcionamento, que irá assegurar a resistência característica $\left(f_{c k}\right)$ requerida no projeto, comprovada após a ruptura, em laboratório e com equipamentos adequados, dos corpos de prova aos 28 dias de idade conforme NBR 5739:2007, [2]. Além da escolha do concreto e do traço mais adequado para cada situação, alguns cuidados devem ser tomados no momento da aplicação do concreto como, assegurar o completo e uniforme preenchimento das formas; adensar o concreto com uso de vibradores de agulha ou réguas vibratórias; iniciar a cura do elemento concretado o mais breve possível; evitar paradas na concretagem para não causar juntas frias; utilizar funil para lançamentos superior a 2,50m; dentre outras [9].

Todavia, apesar do conhecimento já difundido acerca da tecnologia do concreto, diversas aplicações têm apresentado problemas. Ainda são grandes as limitações neste campo do conhecimento, ora por restrições científicas e tecnológicas, ora por falhas involuntárias ou imperícia. A própria qualidade dos materiais empregados tem papel fundamental no que tange o desempenho do produto, gerando a deterioração estrutural [11]. 
Diante o exposto, pretende-se com este estudo analisar qual a causa da falha na concretagem dos pilares do terceiro subsolo de uma edificação multifamiliar localizada na cidade de Caxias do Sul/RS, que deixou exposta sua armadura, descrevendo o caso e os fatos que levaram à percepção desta falha. $O$ relato dos dados de concretagem/concreto do terceiro subsolo, tais como a comparação da resistência requerida em projeto com resistência entregue pelo fornecedor e resistência dos testemunhos é imprescindível para diagnosticar o problema e as consequências geradas na estrutura dessa edificação e poder propor, em conjunto com o calculista estrutural responsável, as ações necessárias para a reparação do problema.

\section{Materiais e métodos}

Para a realização desta pesquisa utilizou-se da investigação de caráter qualitativo, por meio da pesquisa, exploração e descrição de um caso. O método consiste em coletar dados através de observação, revisão documental, discussões com envolvidos nas etapas de execução, a fim de desenvolver uma perspectiva que elucide o porquê da falha de concretagem, objeto deste estudo, [10].

Os dados foram obtidos: 1) dos ensaios de resistências à compressão dos corpos de prova cilíndricos, moldados no dia da concretagem, com $100 \mathrm{~mm}$ de diâmetro, adensados manualmente e curados conforme orientações da ABNT NBR 5738:2015, [1]; 2) de reuniões entre o responsável técnico pela execução da obra, o projetista estrutural e os responsáveis técnicos pela concreteira contratada; 3) de ensaio esclerométrico realizado em três pilares em recuperação (P16, P22 e P24) e dois pilares que não apresentaram a falha (P19 e P21, no subsolo 02), selecionados aleatoriamente como referência; 4) e de testemunhos (amostras retiradas da estrutura do concreto consolidado), conforme NBR 7680:2015, [5]. Os testemunhos foram retirados das etapas 01 e 02 de concretagem dos pilares do subsolo 3 , conforme descrito no próximo capítulo e o resultado apresentado no ensaio.

A fim de complementar a pesquisa, é apresentado o levantamento fotográfico como ferramenta importante para auxiliar na descrição do fato pesquisado, bem como proporcionar maior entendimento ao tema.

\section{Descrição do caso}

O caso analisado ocorreu na cidade de Caxias do Sul, RS - Brasil, em uma construção residencial, com 27 unidades habitacionais, composta por três subsolos e térreo em concreto armado, nove pavimentos de apartamentos e reservatório superior, em alvenaria estrutural com bloco cerâmico (anexo: imagem 01).

A falha foi identificada após a limpeza dos pilares do subsolo três para remoção de poeiras e resquícios de produtos para facilitar a desforma, em preparação para aplicação de camada de acabamento com nata de concreto, meses após a concretagem dos pilares. Com a realização dessa limpeza com jato d'água sob pressão e escova de aço, percebeu-se que o concreto começou a fragmentar no ponto da junta de concretagem, ligação que merece atenção especial para sua realização. 
MUNARO, R; POSSAN, E. FALHA DE CONCRETAGEM DE PILARES E SUAS CONSEQUÊNCIAS NA ESTRUTURA DA EDIFICAÇÃO. $2^{\circ}$ Simpósio Paranaense de Patologia das Construções (20 SPPC), artigo 2SPPC1013, pp. 144-158, 2017. DOI:

À medida que o processo de limpeza evoluiu, parte do concreto da segunda metade da concretagem, se desfez em tamanha porcentagem que expos a armadura de três pilares (P6, P12 e P16, figura 1, 2 e 3, respectivamente) e afetou o cobrimento nos pilares P22, P23 e P24 (figura 4, 5 e 6, respectivamente). (Anexo: imagem 02).

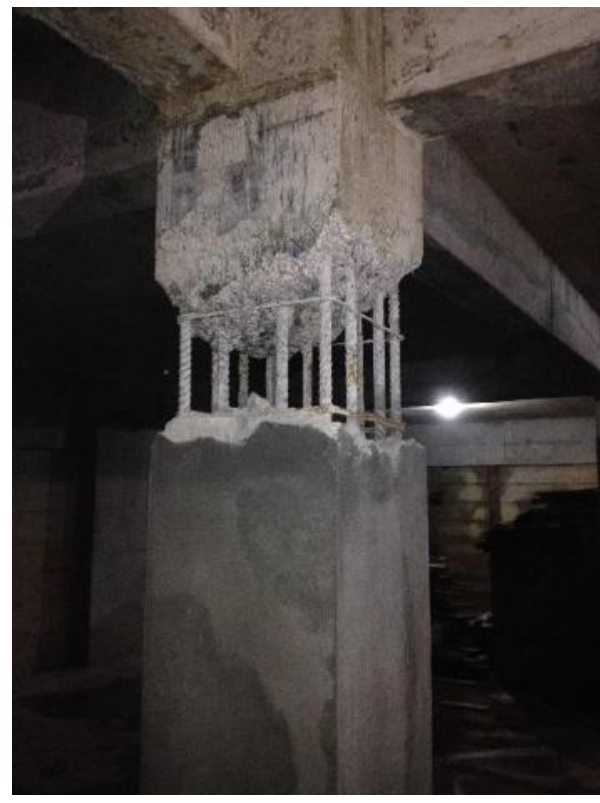

Figura 1: Armadura exposta do pilar 6 (P6). (Fonte: da autora)

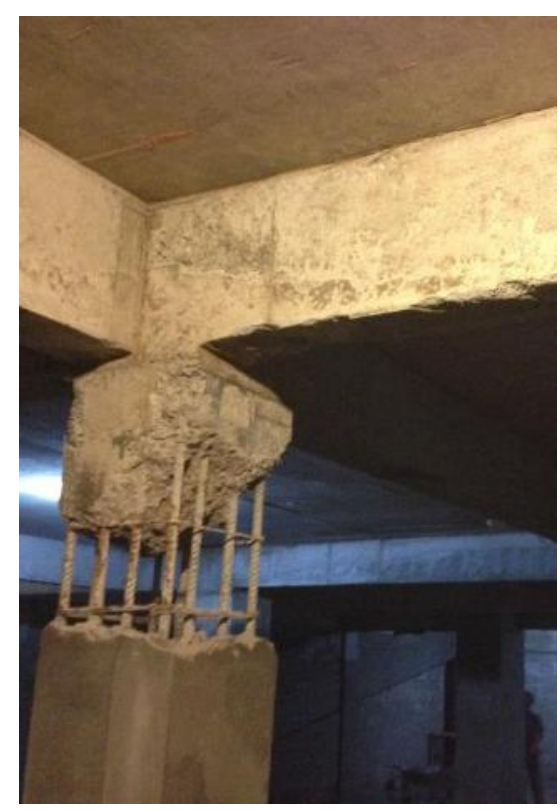

Figura 3: Armadura exposta do pilar 16 (P16) (Fonte: da autora)

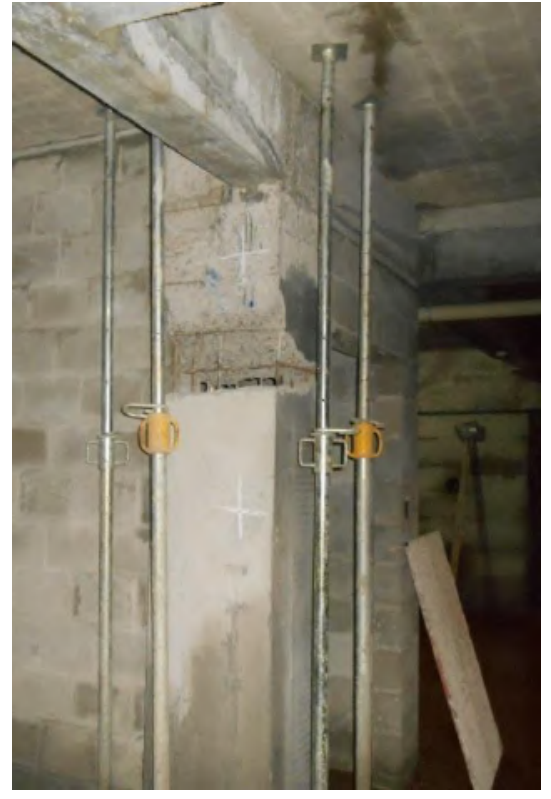

Figura 2: Armadura exposta do pilar 12 (P12). (Fonte: da autora)

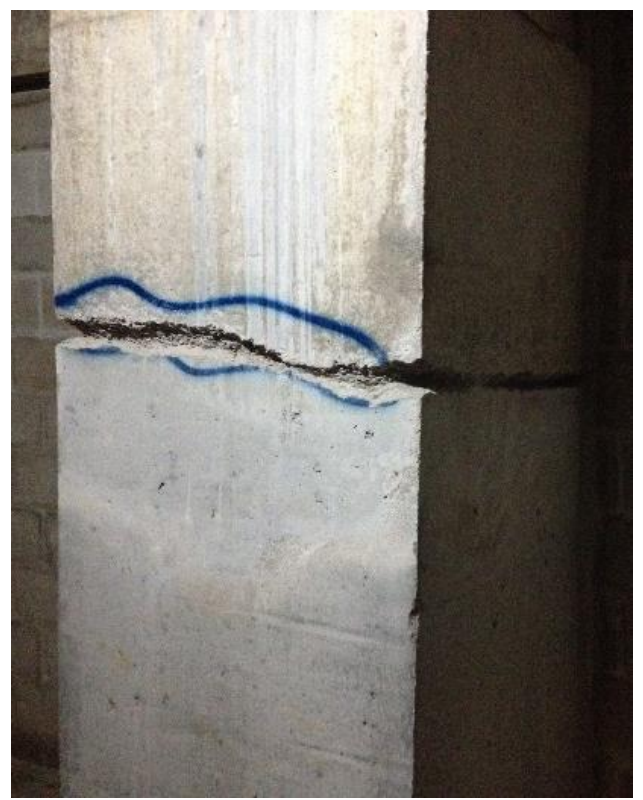

Figura 4: Comprometimento do cobrimento do pilar 22 (P22) (Fonte: da autora) 


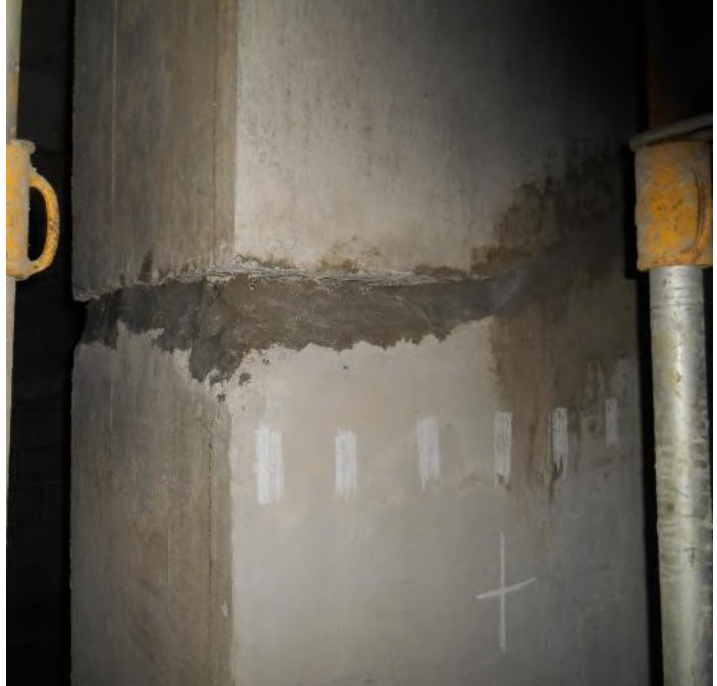

Figura 5: Comprometimento do cobrimento do pilar 23 (P23) (Fonte: da autora)

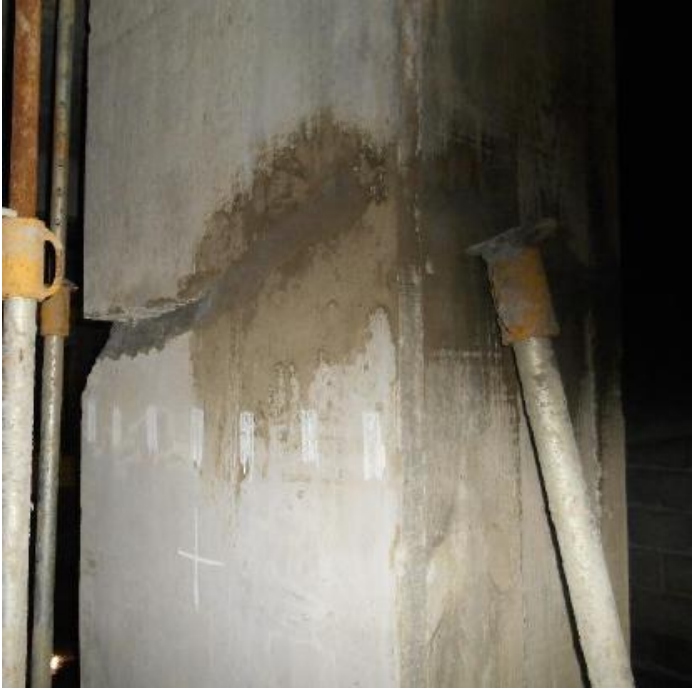

Figura 6: Comprometimento do cobrimento do pilar 24 (P24) (Fonte: da autora)

Sabe-se que os pilares deste pavimento tiveram o concreto lançado em duas etapas em função da altura do pavimento que é de $3,00 \mathrm{~m}$. Na primeira etapa foi realizado o lançamento de concreto auto adensável, com "brita 0" e aditivo para amentar a plasticidade, preenchendo pouco mais da metade de cada pilar, quando este tinha dimensão igual ou superior a $60 \times 60 \mathrm{~cm}$, e $3 / 4$ quando inferior a esta dimensão. $\mathrm{Na}$ segunda etapa, utilizou-se o concreto convencional, CPII, com "brita 1", sem aditivo plastificante, completando os pilares. É importante salientar que entre uma etapa e outra houve precipitação de chuva intensa, o que interrompeu a concretagem na etapa 01 , sendo concretada a etapa 02 somente no dia seguinte, criando a chamada junta fria de concretagem.

Cabe ressaltar que as juntas de concretagem são inerentes à estrutura, mas devese ter cuidados no momento de execução, observando questões estéticas da sua localização, de resistência e durabilidade. Atendendo os requisitos de limpeza da superfície a ser emendada e garantindo a aderência entre as partes, [11]. Segundo Botelho e Marchetti [6], ao executar a junta de concretagem, deve-se atentar à limpeza da superfície do concreto já endurecido, removendo a nata de concretagem e outros resíduos antes do lançamento do novo concreto.

Também se faz necessário manter a superfície irregular, a fim de possibilitar melhor aderência dos concretos e quando necessário, a aplicação de adesivo próprio na junta. A orientação da NBR 6118:2014 [3], item 21.6, nos casos como o descrito, é que devem ser previstas armaduras de costura quando não for propiciada a correta rugosidade da superfície antiga.

Observa-se, nas figuras 7 e 8 que, logo após a constatação da falha e durante 0 processo de limpeza para a realização do reforço estrutural ainda não era possível observar flambagem ${ }^{1}$ da armadura. Como medida preventiva e para evitar danos

\footnotetext{
${ }^{1}$ Flambagem: Termo usado para designar a encurvadura de um elemento estrutural.
} 
maiores, em conjunto com a limpeza dos pilares, foi iniciado o escoramento da estrutura.

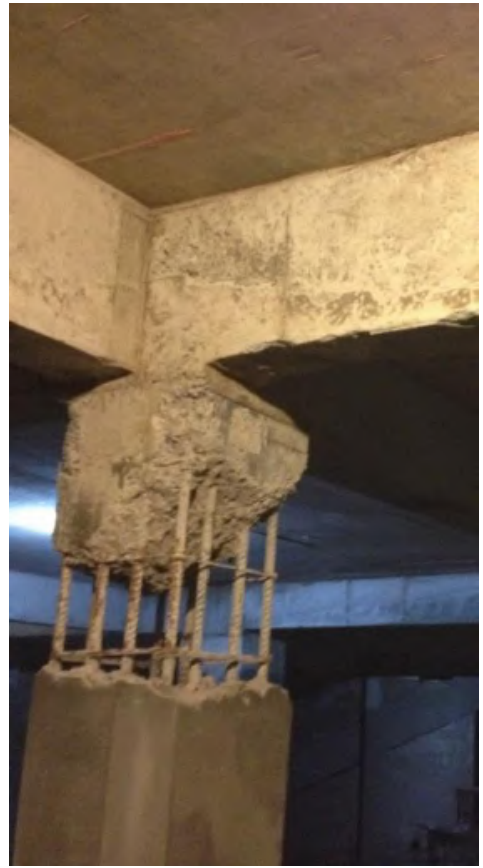

Figura 7: P16, sem apresentar flambagem aparente na armadura (fonte: da autora)

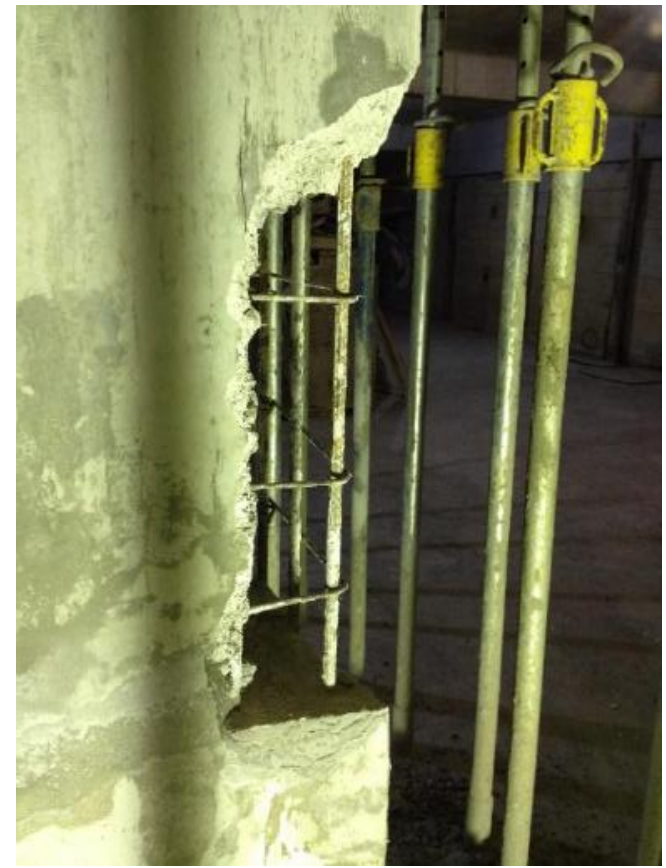

Figura 8: P24, sem apresentar flambagem aparente na armadura (fonte: da autora)

Mesmo com a estrutura escorada, durante o período de estudos e discussão de causas do problema e melhor forma de reparar a estrutura, nota-se que a armadura do pilar P06, apresentou flambagem ${ }^{1}$ (figura 9), mesmo com o escoramento realizado, a fim de distribuir a carga suportada pelo pilar P06. Este fenômeno somente foi percebido no pilar onde a armadura exposta tem maior proporção em relação ao concreto aparentemente saudável. Neste pilar já havia sido dado início à escarificação ${ }^{2}$ da estrutura, preparo preliminar para garantir a aderência do novo concreto de reparação.

A fim de controlar e registrar condições e fatos de todo o processo de concretagem da obra é preenchida uma planilha, chamada de rastreabilidade do concreto, um documento importante no processo de execução da obra que apontando onde foi utilizado cada volume do concreto recebido, além de informações pertinentes, como obra, data/horário, responsável, aplicação/pavimento, volume, resistência ( $f_{c k}$ ) requerida, dentre outros dados. Esse documento propiciou a localização das informações sobre o concreto aplicado no terceiro subsolo e deu início a investigação. Faz parte da rastreabilidade do concreto o croqui do local de lançamento do concreto (Anexo: imagem 03 e 04)

\footnotetext{
2 Escarificação: Série de arranhões ou pequenas incisões praticadas sobre uma superfície, para garantir rugosidade e aderência
} 


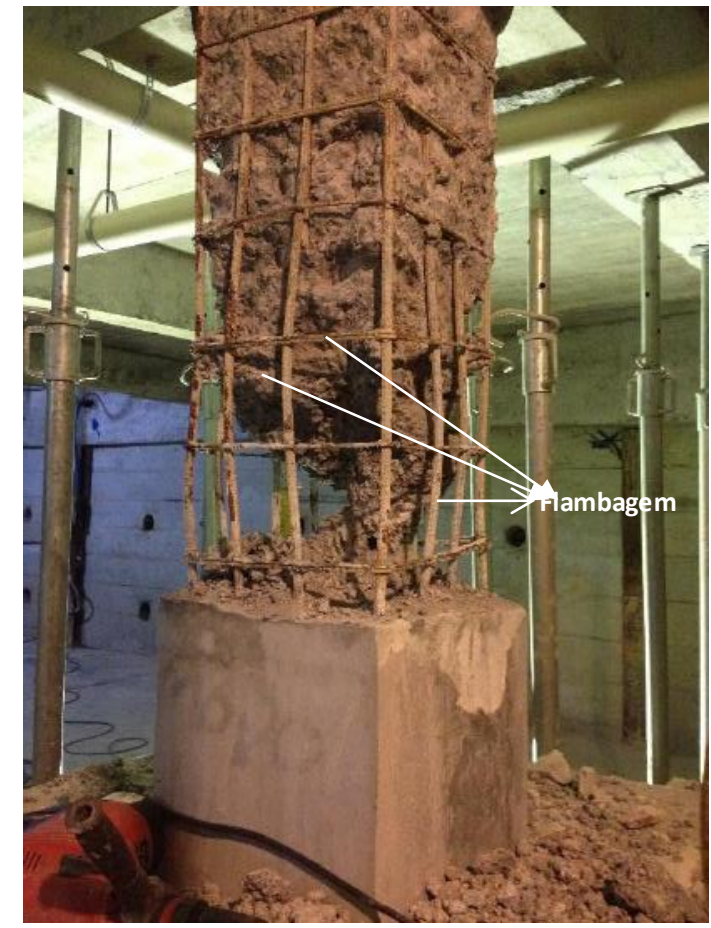

Figura 9: P6, apresentação de flambagem da armadura (fonte: da autora)

Ao ser constatada a falha no terceiro subsolo, os três pavimentos superiores (segundo subsolo, primeiro subsolo e térreo) já haviam sido executados e encontravam-se na etapa inicial de elevação da alvenaria. Fator de grande preocupação, pois a carga imposta sobre os pilares fragilizados colocou em risco vidas de operários da obra e poderia causar danos irreversíveis na estrutura.

\section{Resultados e discussão}

Com a constatação do problema nos pilares, a primeira ação foi analisar os resultados dos ensaios dos corpos de prova desta concretagem onde ocorreu a constatação que a resistência à compressão aos 28 dias de idade $\left(f_{c j}\right)$ continha resultados abaixo do solicitado em projeto estrutural ( $\left.f_{c k}\right)$, estabelecido em $30 \mathrm{MPa}$. Através desse resultado foi solicitado imediatamente o ensaio da contraprova, moldada em conjunto com os corpos de prova de cada volume de concreto do dia da concretagem. Neste momento, com resultados igualmente abaixo do requisitado com mais de 150 dias de idade do concreto, se amplia a investigação, através a extração de testemunhos para encaminhamento para ensaio de compressão.

Foram extraídos ao todo 12 testemunhos dos pilares. Pilar 6 (P6), pilar 24 (P24), pilar 29 (P29) e pilar 30 (P30) a extração foi realizada somente da segunda etapa de concretagem, com concreto convencional. Já os pilares 12 (P12), pilar 16 (P16), pilar 22 (P22) e pilar 23 (P23) foram extraídos testemunhos das duas etapas de concretagem, com concreto auto adensável na primeira etapa e convencional na segunda etapa. Esta definição foi passada pelo calculista estrutural, de acordo com os esforços que cada pilar foi projetado a suportar, mais esforço dois testemunhos, menos esforço, um testemunho. 
A tabela 1 apresenta um comparativo das resistências encontradas em cada ensaio, para os pilares que apresentaram problemas. Observa-se que na $2^{\underline{a}}$ etapa da concretagem se encontram as menores resistências à compressão, tanto nos corpos de prova quanto nos ensaios dos testemunhos. A tabela apresentada divide os pilares por etapa de concretagem, tipo de concreto e nota fiscal de cada caminhão betoneira utilizado nestes pilares.

Também houve a realização de ensaio não destrutivo de esclerometria, de acordo com a NBR 7584:2012, [4]. O ensaio foi realizado nos pilares P19, P22 e P24 do terceiro subsolo e pilares P16 e P21, no segundo subsolo. O resultado deste ensaio pode-se comparar com os resultados anteriores e contatou-se que ficaram abaixo dos resultados dos corpos de prova na etapa 02 da concretagem, abaixo também da resistência requerida em projeto, de $30 \mathrm{MPa}$.

Tabela 1: Quadro comparativo de resistência do concreto de acordo com ensaios de laboratório. (fonte: elaborada pela autora)

\begin{tabular}{|c|c|c|c|c|c|c|c|c|c|}
\hline \multirow{3}{*}{\multicolumn{2}{|c|}{$\begin{array}{l}\text { Etapas da } \\
\text { concretagem } \\
\text { subsolo } 03\end{array}$}} & \multirow{3}{*}{$\begin{array}{c}\text { Identificação } \\
\text { dos pilares }\end{array}$} & \multirow{3}{*}{ NF } & \multirow{3}{*}{$f_{c k}$} & \multicolumn{5}{|c|}{ Fcj estimado (MPa) } \\
\hline & & & & & \multicolumn{2}{|c|}{$\begin{array}{c}\text { Ensaio } \\
\text { regular } \\
\text { (28 dias) }\end{array}$} & \multirow{2}{*}{$\begin{array}{c}\text { Contraprova } \\
\text { (150 dias) }^{1}\end{array}$} & \multirow[t]{2}{*}{$\begin{array}{l}\text { Teste- } \\
\text { munhos }\end{array}$} & \multirow[t]{2}{*}{$\begin{array}{l}\text { Escle- } \\
\text { rômetro }\end{array}$} \\
\hline & & & & & CP1 & CP2 & & & \\
\hline \multirow{6}{*}{\multicolumn{2}{|c|}{$\begin{array}{l}\text { 1a etapa: } \\
\text { concreto } \\
\text { auto } \\
\text { adensável }\end{array}$}} & $\mathrm{P} 6$ & \multirow{6}{*}{2359} & \multirow{6}{*}{$\begin{array}{l}30 \\
30 \\
30 \\
30 \\
30 \\
30\end{array}$} & \multirow{6}{*}{\multicolumn{2}{|c|}{61,28}} & \multirow{6}{*}{77,73} & - & $x$ \\
\hline & & P12 & & & & & & 84,07 & $\mathrm{X}$ \\
\hline & & P16 & & & & & & 82,00 & $X$ \\
\hline & & P22 & & & & & & 46,17 & 47,00 \\
\hline & & P23 & & & & & & 32,19 & $X$ \\
\hline & & P24 & & & & & & - & 36,00 \\
\hline \multirow{6}{*}{\multicolumn{2}{|c|}{$\begin{array}{l}\text { 2a etapa: } \\
\text { concreto } \\
\text { convencional }\end{array}$}} & $\mathrm{P} 6$ & \multirow{2}{*}{2384} & \multirow{2}{*}{\begin{tabular}{|l|}
30 \\
30 \\
\end{tabular}} & \multirow{2}{*}{\multicolumn{2}{|c|}{29,52}} & \multirow{2}{*}{$x$} & 26,66 & $\mathbf{X}$ \\
\hline & & P16 & & & & & & 28,42 & $\mathbf{X}$ \\
\hline & & $\mathrm{P} 12$ & 9705 & 30 & 20,4 & & 27,03 & 22,01 & $\mathbf{X}$ \\
\hline & & P22 & \multirow{2}{*}{9699} & \multirow{2}{*}{\begin{tabular}{|l|}
30 \\
30
\end{tabular}} & \multirow{2}{*}{\multicolumn{2}{|c|}{30,11}} & \multirow{2}{*}{$x$} & 35,73 & 27,00 \\
\hline & & P23 & & & & & & 33,15 & $\mathrm{x}$ \\
\hline & & P24 & 9702 & 30 & 25,1 & & $x$ & 28,87 & 21,00 \\
\hline \multirow{2}{*}{\multicolumn{2}{|c|}{ Subsolo 02}} & P16 & 1557 & 30 & 33,9 & & $x$ & - & 33,00 \\
\hline & & $\mathrm{P} 21$ & 1559 & 30 & 34,0 & & $x$ & - & 31,00 \\
\hline$x$ & \multicolumn{9}{|c|}{ CP ou testemunho fissurado - não ensaiado } \\
\hline- & \multicolumn{9}{|c|}{ não extraído testemunho } \\
\hline * & \multicolumn{9}{|c|}{ objeto de estudo, pilares com falha } \\
\hline 1 & \multicolumn{9}{|c|}{ Corpo de prova rompido aos 150 dias de idade } \\
\hline
\end{tabular}

Sabe-se também, que o concreto recebido para as duas etapas da concretagem, além de ser de tipologia diferente, auto adensável e convencional, o que não deprecia a aplicação, desde que dosado e aplicado de forma adequada, foi enviado pela mesma empresa concreteira, porém de unidades distintas, percebido pela 
numeração das notas fiscais, com valores mais baixos na primeira e avançados na segunda etapa e validado pela empresa fornecedora do concreto.

A segunda etapa de lançamento do concreto ainda ocorreu no dia seguinte, pois a obra teve de ser interrompida devido à forte chuva que atingiu a cidade no dia de concretagem. Ao ser retomada a concretagem dos pilares, não foi realizada a limpeza da nata de concreto formado na superfície do concreto antigo, já em processo de cura, tampouco houve escoamento da água acumulada na fôrma (em função da chuva). Além da falta de conferência e execução de rugosidade do antigo concreto para possibilitar a aderência do novo concreto e a execução de armadura de costura.

Para recuperação, após serem refeitos os cálculos das exigências dos esforços aplicados nos pilares, foi proposto preenchimento das lacunas de concreto dos pilares P06, P12 e P16 (figuras 10 e 11), de menor dimensão, com aumento da seção na região próxima das vigas e reforço com armadura e também aumento de seção nos pilares P22, P23 e P24 Nota-se no pilar P24 que houve a remoção do concreto degradado e consequente criação de superfície rugosa para melhorar aderência do novo concreto utilizado, o chamado grout, (figura 12 e 13). A aplicação se deu através do pavimento superior, através de furos na laje (figura 14), próximo à base do pilar.

A escolha do grout foi definida pela fácil aplicação, devido sua fluidez, e elevada resistência mecânica [11]. Antes da aplicação, foi observado a correta limpeza da superfície com jatos de água, removendo poeiras e outras partículas que poderiam afetar a adesão do concreto novo com o antigo. Esse procedimento foi adotado para a recuperação dos demais pilares afetados.

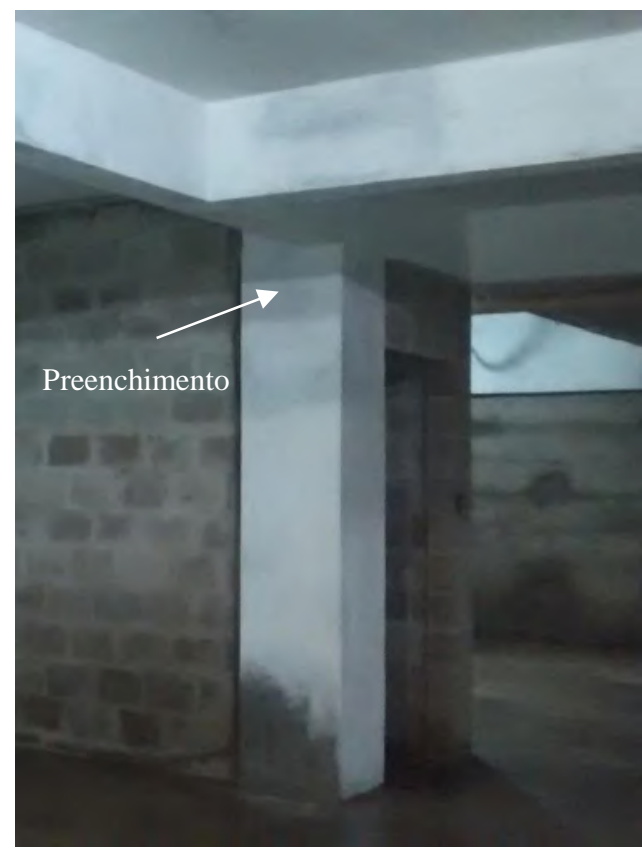

Figura 10 :Preenchimento com grout da falha de concretagem no pilar P12.

(fonte: da autora)

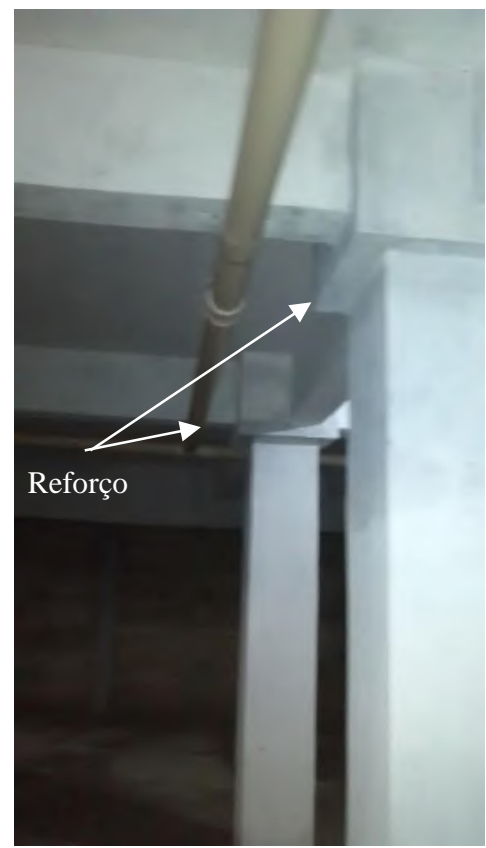

Figura 11: Reforço com grout nos pilares P06 e P16. (fonte: da autora) 


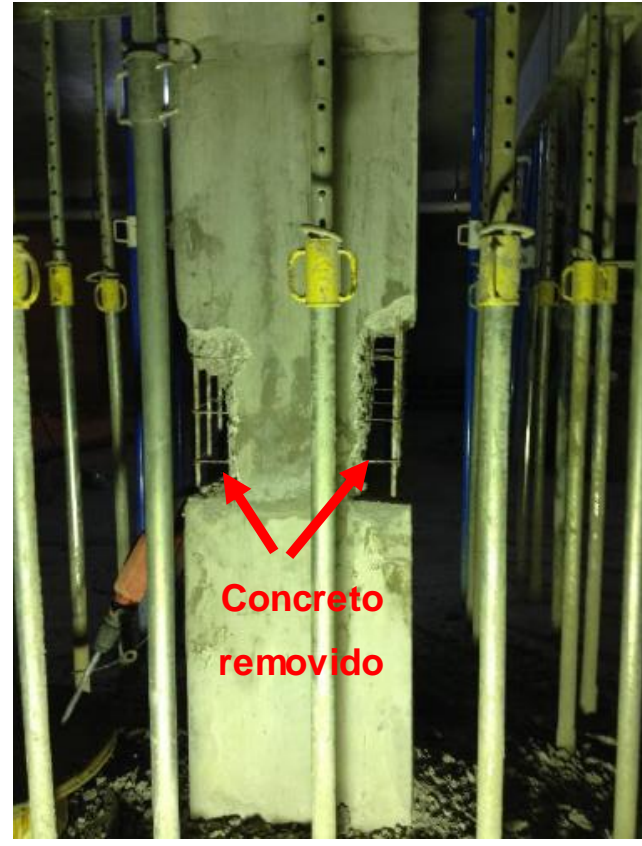

Figura 12: Remoção do concreto degradado e criação de supercície rugosa. (fonte: da autora)

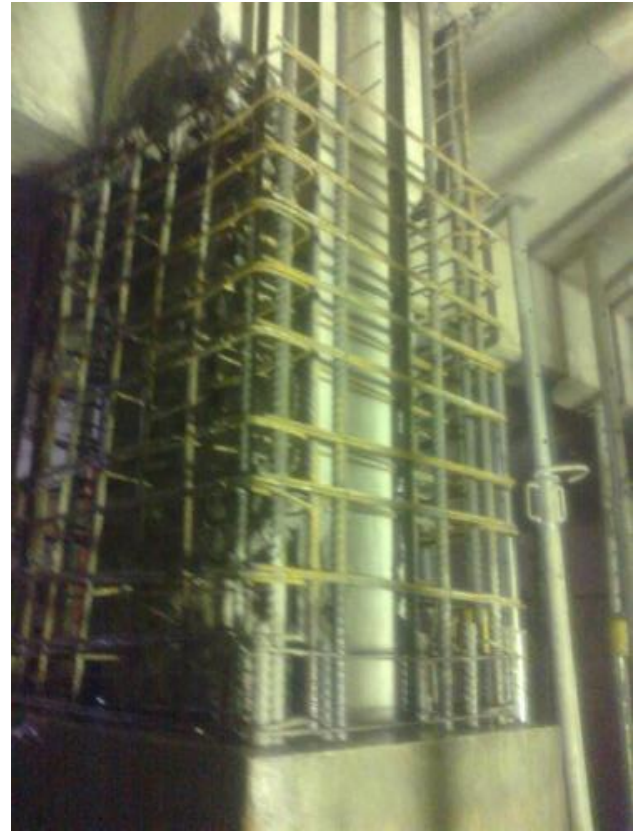

Figura 13: Reforço de armadura no pilar P24. (fonte: da autora)

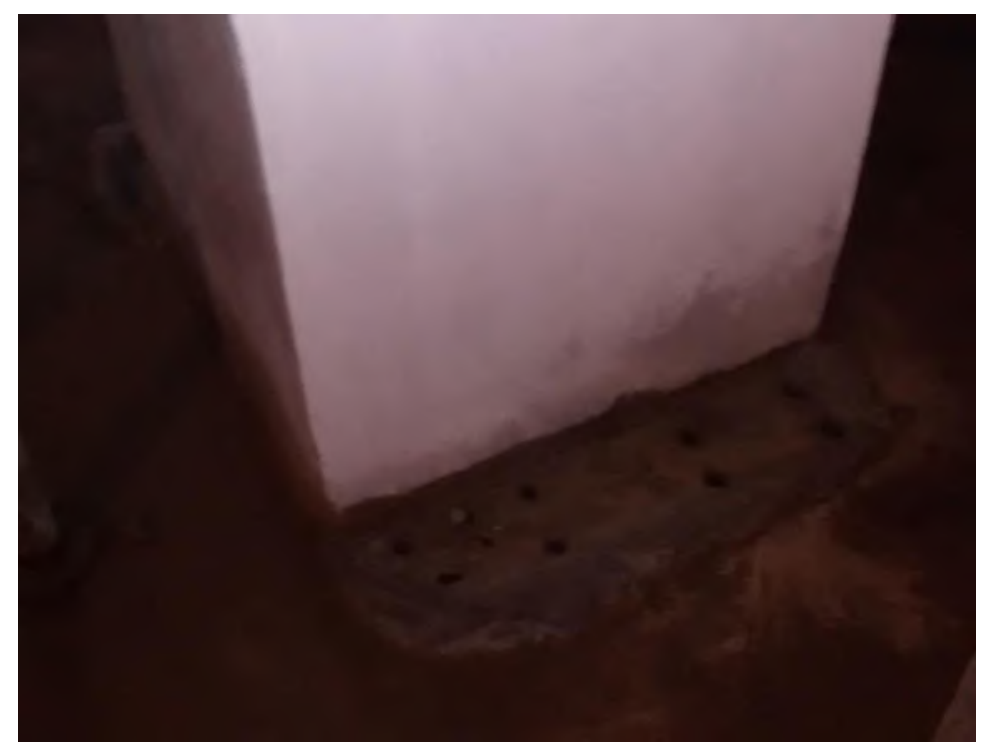

Figura 14: Furos no segundo subsolo para aplicação do grout nos pilares do pavimento do terceiro subsolo. (fonte: da autora)

Foi realizado o monitoramento da estrutura e das possíveis consequências no pavimento superior, segundo subsolo, e não foi identificada nenhuma manifestação patológica causado pelo problema apresentado.

\section{Conclusão}

Os resultados deste trabalho permitem a reflexão sobre as deficiências no setor da construção civil, que independente dos processos de controle e registros da 
execução de cada etapa da obra e também dos muitos avanços tecnológicos que qualificam cada vez mais a matéria empregada na construção, ainda é tida como uma atividade artesanal ou pouco industrializada. Os recursos humanos que atuam no setor e executam os projetos, possuem as mais variadas habilidades, ou falta delas, sendo passível a ocorrência da falha humana, agente com grande carga de responsabilidade sobre os problemas apresentados.

A partir da análise dos ensaios realizados, dos dados levantados e estudo de bibliografias sobre o tema, foi possível apurar as principais causas para os problemas dos pilares mencionados sendo possível apontar dois fatores principais, um de caráter tecnológico e outro humano. A deficiência na dosagem do concreto na central sendo percebida através dos baixos resultados dos ensaios de compressão, demonstrando um equívoco ao quantificar e especificar os agregados e produtos para a composição do concreto convencional, pois mesmo com mais de 150 dias de cura ele não atingiu a resistência requerida. A parcela humana sobre a degradação dos pilares, associada com concretagem em dias distintos, propiciou a união entre o concreto endurecido com o novo sem a adequada execução dos processos recomendados para essa situação e citadas em capítulos anteriores.

Percebe-se que o processo construtivo demanda atenção especial e ainda requer muito estudo e pesquisas, a fim de minimizar as ocorrências patológicas e evitar desperdício de tempo e recursos, humanos, materiais e financeiros.

\section{Referências Bibliográficas}

[1] Associação Brasileira de Normas Técnicas. NBR 5738: Versão Corrigida:2016 - Concreto - procedimento para moldagem e cura de corpos-de-prova. Rio de Janeiro, 2015.

[2] NBR 5739: Concreto - ensaios de compressão de corpos de prova cilíndricos. Rio de Janeiro, 2007.

[3] NBR 6118: Projeto de estruturas de concreto - Procedimento. Rio de Janeiro, 2014.

[4] NBR 7584: Concreto endurecido - Avaliação da dureza superficial pelo esclerômetro de reflexão. Rio de Janeiro, 2012.

[5] NBR 7680:2015 - Concreto - Extração, preparo, ensaio e análise de testemunhos de estrutura de concreto. Rio de Janeiro, 2015.

[6] BOTELHO, M.H.B e MARCHETTI, O; Concreto armado, eu te amo. Vol: 2; São Paulo: Blucher, 2010

[7] LEONHARDT. F e MÖNNIG, E. Construções de concreto. Vol: princípios básicos do dimensionamento de estruturas de concreto armado/ tradução de David fridman, 2 reimpr. - Rio de Janeiro: interciência, 2008.

[8] METHA, P.K.; MONTEIRO, P.J.M. Concreto: microestrutura, propriedades e materiais. 3.ed. Nicole Hasparyk; Paulo Helene; Vladiir Paulon (ver. Trad.) São Paulo: IBRACON, 2008. 674p

[9] SALGADO, J.C.P.; Técnicas e Práticas construtivas para edificação. 2.ed. São Paulo: Erica, 2009. 
MUNARO, R; POSSAN, E. FALHA DE CONCRETAGEM DE PILARES E SUAS CONSEQUÊNCIAS NA ESTRUTURA DA EDIFICAÇÃO. $2^{\circ}$ Simpósio Paranaense de Patologia das Construções (20 SPPC), artigo 2SPPC1013, pp. 144-158, 2017. DOI:

[10] SAMPIERI, R.H; COLLADO, C.F. e LUCIO, M.P.B; Metodologia de pesquisa. Tras. Deyse Vaz de Moraes. México: Penso, 2013.

[11] SOUZA, V.C.M; Patologia, recuperação e reforço de estruturas de concreto; São Paulo: PINI, 1948;

[12] TUTIKIAN, B.F; DAL MOLIN, D. Concreto auto-adensável. São Paulo: Pini, 2008. 
MUNARO, R; POSSAN, E. FALHA DE CONCRETAGEM DE PILARES E SUAS CONSEQUÊNCIAS NA ESTRUTURA DA EDIFICAÇÃO. $2^{\circ}$ Simpósio Paranaense de Patologia das Construções (20 SPPC), artigo 2SPPC1013, pp. 144-158, 2017. DOI:

\section{ANEXO I \\ CORTE LONGITUDINAL ESQUEMÁTICO}

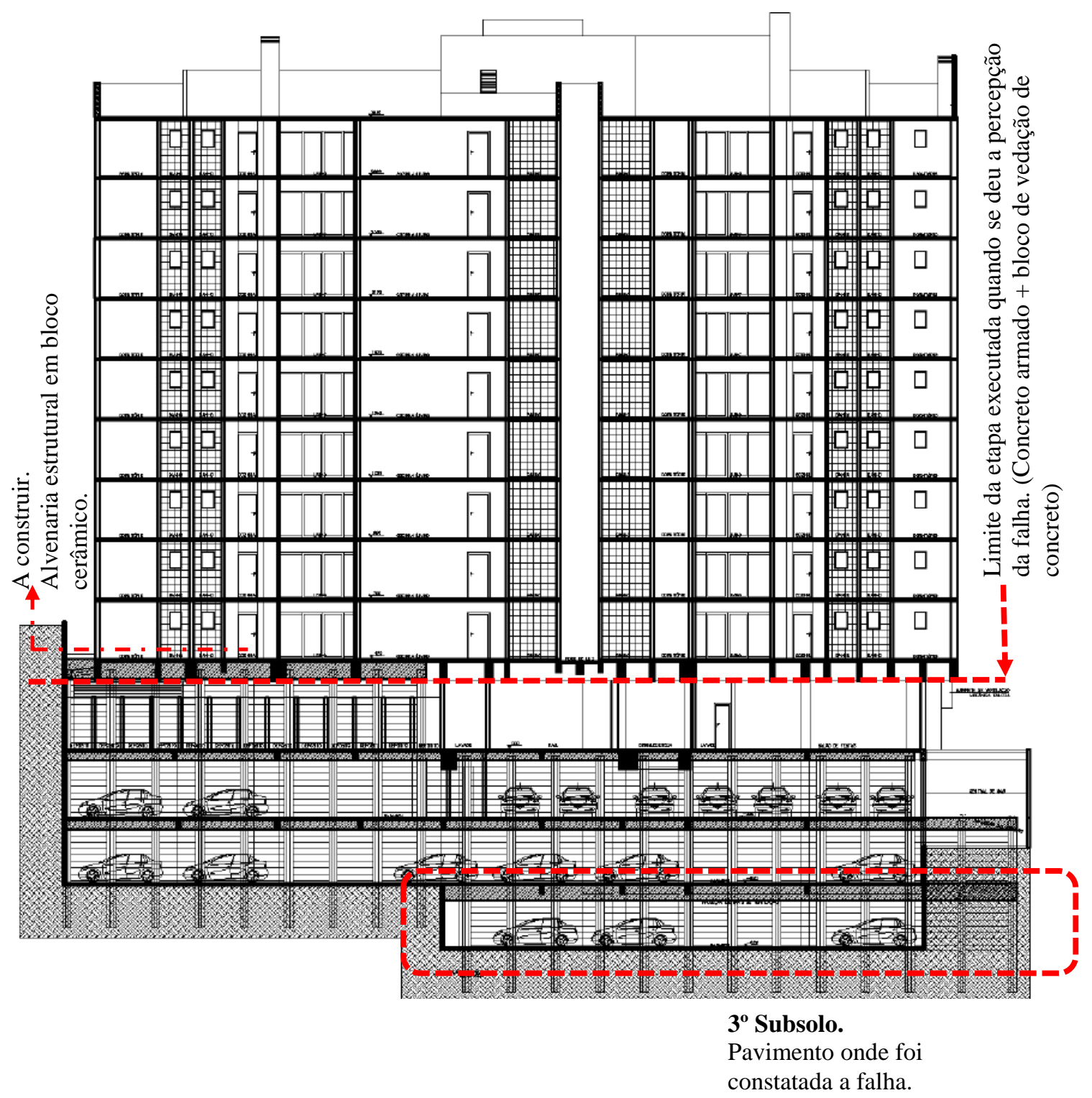


MUNARO, R; POSSAN, E. FALHA DE CONCRETAGEM DE PILARES E SUAS CONSEQUÊNCIAS NA ESTRUTURA DA EDIFICAÇÃO. $2^{\circ}$ Simpósio Paranaense de Patologia das Construções (20 SPPC), artigo 2SPPC1013, pp. 144-158, 2017. DOI:

\section{ANEXO II \\ PLANTA DE LOCALIZAÇÃO DOS PILARES DO TERCEIRO SUBSOLO}

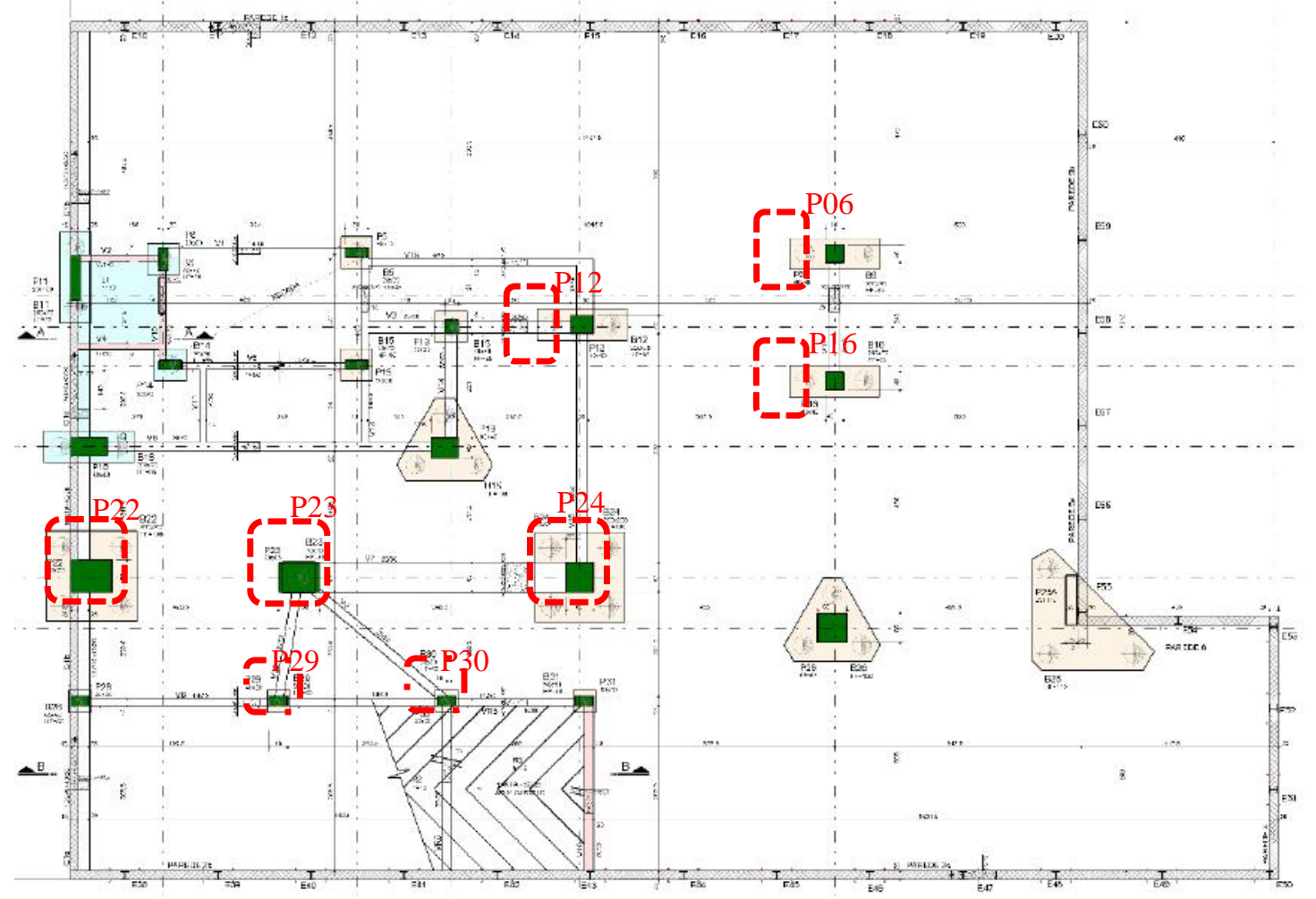


MUNARO, R; POSSAN, E. FALHA DE CONCRETAGEM DE PILARES E SUAS CONSEQUÊNCIAS NA ESTRUTURA DA EDIFICAÇÃO. $2^{\circ}$ Simpósio Paranaense de Patologia das Construções (20 SPPC), artigo 2SPPC1013, pp. 144-158, 2017. DOI:

\section{ANEXO III \\ RASTREABILIDADE DO CONCRETO, PLANILHA DE DADOS (FONTE: RESPONSÁVEL TÉCNICO DE EXECUÇÃO)}

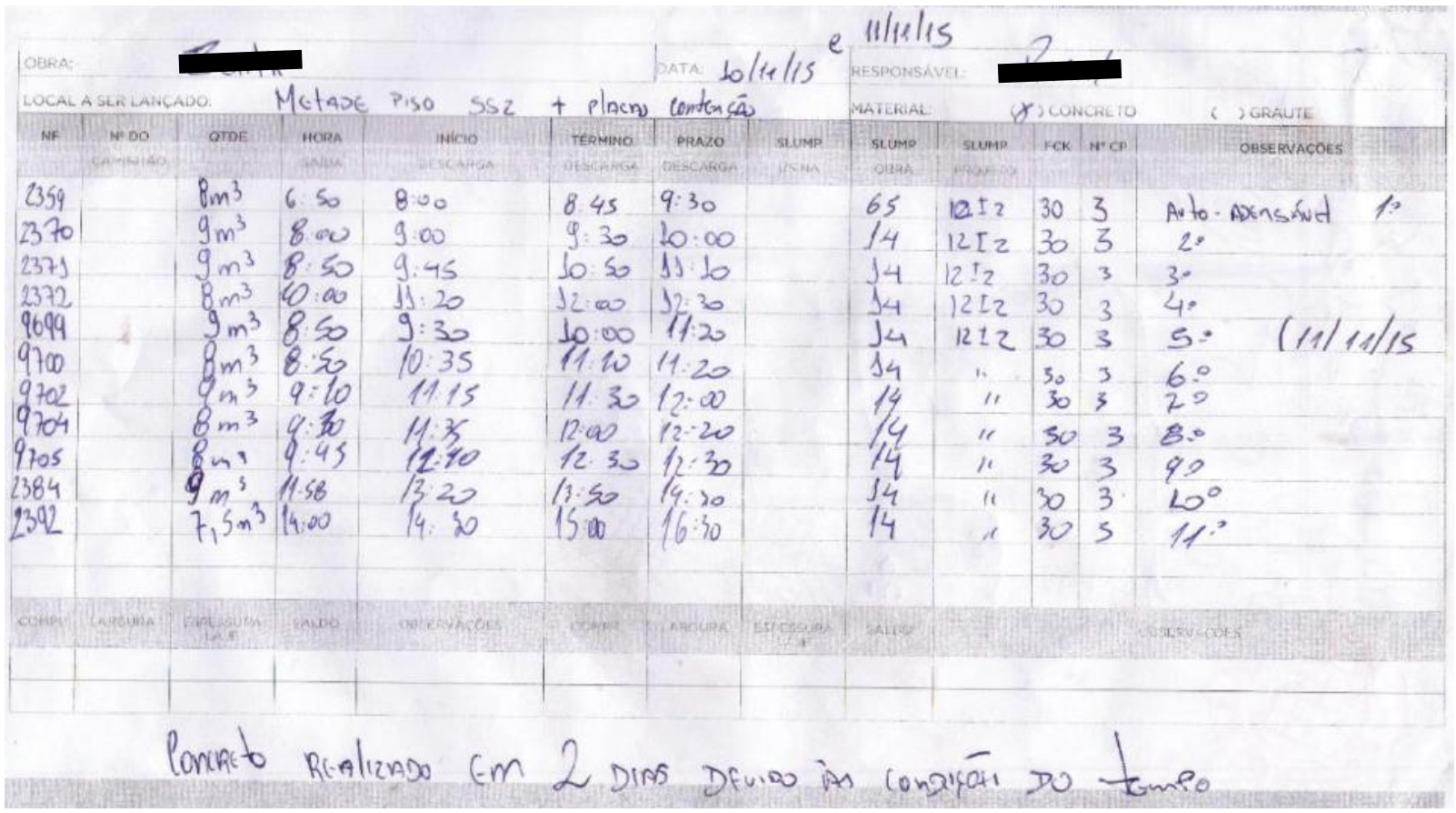

\section{ANEXO IV \\ CROQUIS DE LANÇAMENTO DO CONCRETO (FONTE: RESPONSÁVEL TÉCNICO DE EXECUÇÃO)}

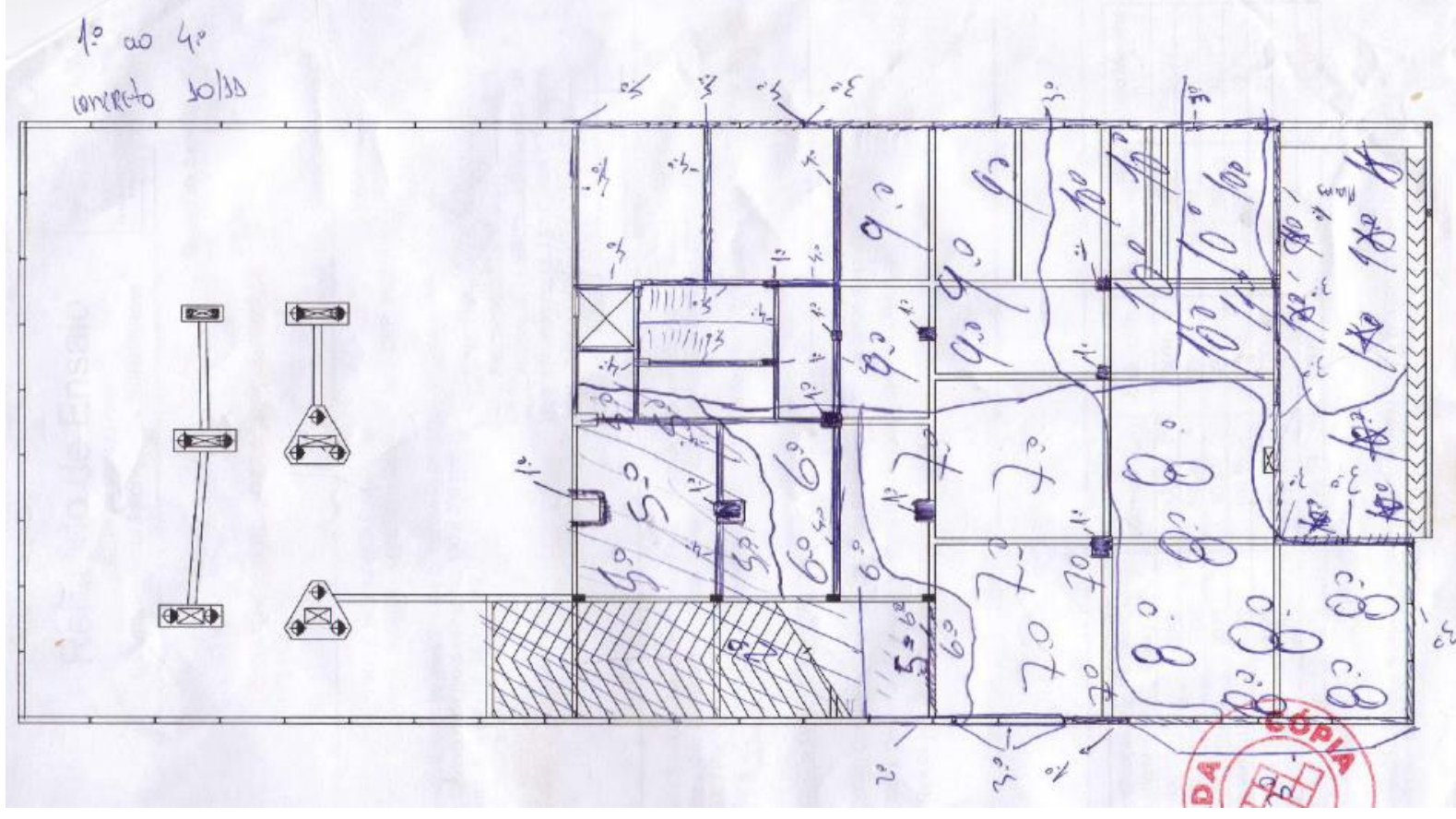

